\title{
Aspects of long-term durability of reinforced concrete structures in marine environments
}

\author{
Robert E Melchers - Torill Pape
}

Centre for Infrastructure Performance and Reliability, The University of Newcastle, Australia. rob.melchers@newcastle.edu.au

torill.pape@newcastle.edu.au

ABSTRACT. Much concern exists about the apparently short durability of reinforced concrete structures in marine environments. However, there are structures that have survived for long periods of time with little evidence of reinforcement corrosion. Some of these were made with seawater as mixing water and had very little concrete cover. Detailed examination has revealed that reinforced concrete structures made with fine or coarse aggregate consisting of calcium carbonates such as limestone or seashells or with non-reactive dolomite have delayed times to corrosion initiation and to active corrosion. The reasons for this are explored herein. It is shown also that some structures can have serious localized reinforcement corrosion without obvious exterior signs such as concrete cracking and delamination. This requires urgent research.

KEY WORDS: Corrosion, seawater, reinforcement, concrete, structures.

\section{Introduction}

In the following it will be suggested that despite much research and the well-established conventional view that the expected life on reinforced concrete structures depends on the rate of ingress of aggressive chloride ions to the reinforcement through the concrete cover and/or on the rate of carbonation, there are some puzzling inconsistencies. Many 'modern', apparently well-designed reinforced concrete structures in aggressive marine environments are showing signs of reinforcement corrosion and, overall, appear to have shorter serviceable lives than might be expected, at least compared to older reinforced concrete structures. This often is attributed to poor workmanship, insufficient concrete cover and on changes in cement-making practices. The latter refers to the higher clinkering temperatures and the finer grinding of cement to give higher early-strength cements and permitting, in some countries at least, lower cement contents in concrete. There are claims to support correlation between these factors, but close scrutiny of the data does not support the case (Melchers and Li 2009a). Moreover, many older concrete structures with thin cover and no claim to good workmanship have survived well while many modern structures have not. 
As will be illustrated below, there are many cases where the long-term durability of reinforced concrete is inconsistent with the conventional wisdom. This suggests that not al! is understood, currently, about the long-term durability of reinforced (and prestressed) concrete. Better understanding of the long-term durability of concrete structures can be obtained only through careful and detailed examination of actual structures rather than artificially accelerated laboratory tests. More cognisance must be taken of the (electro-) chemistry of the whole of the steel-cement-aggregates-moisture-ion/solution combination, including the possible effects of bacteria.

It will be assumed that the reader is familiar with the conventional wisdom of reinforcement corrosion as summarized in texts such as Richardson (2002), Hunkeler (2005) and Gjorv (2009). The next two sections give examples of the inconsistency of the conventional wisdom with some observations for actual structures. These led to the present research. An overview of a very extensive literature survey of reports of the behaviour of actual, as distinct from laboratory, observations of the behaviour of reinforced concrete structures is then given. This indicates that long-term durability requires availability of a high level of buffering of concrete $\mathrm{pH}$. This is promoted by the use of alkaline aggregates such as limestone and non-reactive dolomites. Also a further, previously unpublished, example is presented. The paper closes with a brief discussion of the likely reasons for the various observations.

\section{Arbroath Balustrade, Scotland}

The reinforced concrete balustrade at Arbroath breaks all the conventional rules for achieving high quality concrete (Melchers et al. 2009, Melchers and Li 2009b). Its 1943 concrete is full of seashells, almost certainly indicating the use of local beach sand and seawater for mixing water. Thus high levels of chlorides were present in the concrete right from the start. The concrete cover, nominally only $25 \mathrm{~mm}$, was found in samples broken open in 2008 to be highly variable and often much less than the nominal cover. Also, the aggregate grading was highly variable. The around 1000 identical balustrade segments, each over $2 \mathrm{~m}$ long and nominally $150 \times 150 \mathrm{~mm}$ in cross-section were made under wartime conditions, probably volume mixed in small batches using a smaller mixer and made under variable weather conditions. Thus considerable availability could be expected in initiation of reinforcement corrosion. The balustrade is immediately next to the North Sea and waves spill over it during winter storms. Despite all this, some $90 \%$ of the original 1943 balustrade segments were still in place and in superficially good condition in 2006, more than 60 years after construction. Few showed signs of corrosion initiation such as spalling, delamination or rust staining. The other $10 \%$ of the balustrade consists of replacements, installed in 1968 and 1993. These have similar concrete cover but show better workmanship. These elements were made when seawater as a mixing water was banned. Despite these more favourable characteristics, when inspected in 2006 and in 2008 many of these elements were badly corroded and showing severe longitudinal concrete cracking.

Subsequent detailed investigation of several samples produced some unexpected results. Segments of balustrade were cut across with a diamond saw and immediately tested for 
concrete pH. For the 1968 and 1993 concretes no obvious reinforcement corrosion was found where the concrete $\mathrm{pH}$ was greater than about 10 (Melchers and Li 2009c). Only when the $\mathrm{pH}$ was less than about 9.5 was there corrosion. However, for the 1943 concrete no corrosion was found in some cross-sections with concrete $\mathrm{pH}$ down to 7.5 and in others, where corrosion had initiated, the $\mathrm{pH}$ immediately adjacent to the corroding bars was around 8.5. In contrast, the conventional wisdom is that reinforcement corrosion initiates when the $\mathrm{pH}$ drops below about 10 (e.g. Gjorv 2009).

Several segments of 1943 balustrade, in good external condition, without obvious cracking, were broken open longitudinally. Mostly the reinforcement was in excellent condition and similar to when the concrete was first cast. One of the segments, however, was completely different. Part-way along the segment, one of the reinforcing bars disappeared, with only a thin black stripe remaining along the path where the reinforcing bar had been, as evident from the cavity left behind (Figure 1). Close inspection showed a very fine crack across the segment at about the location where the reinforcing bar suddenly 'disappeared'. Small areas of rust staining were observed on the concrete surfaces adjacent to the 'disappeared' bar, with appearance of dried-up puddles of rust stain (Figure 1, right).

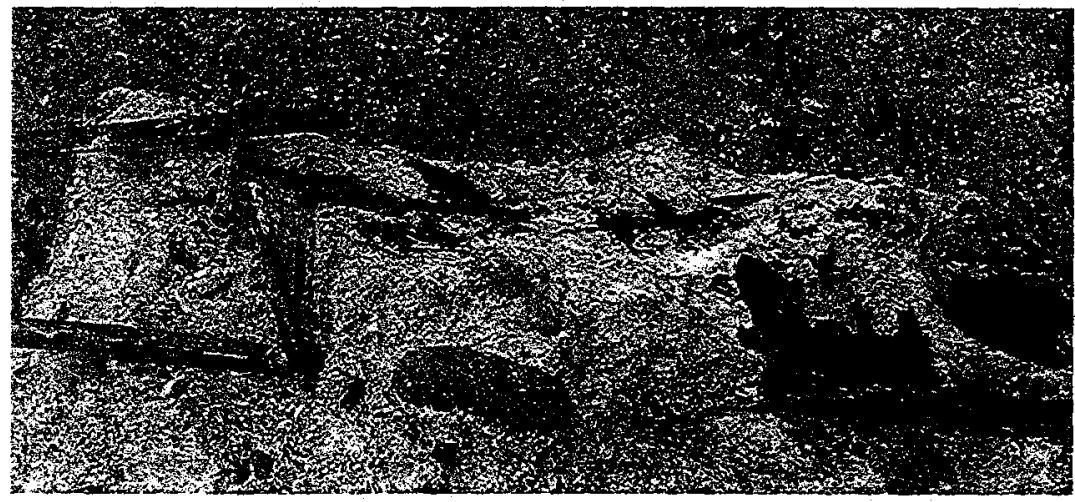

Figure 1. Bars at left show no sign of corrosion after 65 years exposure but bar at centre top has completely corroded leaving a black trace. Note 'dried puddles' of rust stain at right.

\section{Sorell Bridge, Tasmania}

A multi-span, multi-beam $457 \mathrm{~m}$ long 34 span prestressed concrete bridge over a tidal inlet constructed in 1956 was demolished in 2002. Reinforcement prestressing tendon corrosion was first detected in 1976. Low concrete cover $(25 \mathrm{~mm})$ and the lack of a prestressing duct appeared responsible. Three beams of this bridge have been examined in considerable detail (Pape and Melchers 2008). A most remarkable observation, however, 
was the substantial loss of steel of one of the main tendons, up to $75 \%$ for some of the tendon strands, without significant amounts of local rust build-up. Only in some parts of the beams showed cracking, along the beam web, along the profile of the tendon. There was little external rust staining. However, a longitudinal crack, with rust staining, was found at the lower flange of the most severely damaged beam. However, cracking along the tendon profile was much less than might have been expected. Moreover, the spaces between the strands and the surrounding concrete had not been filled completely with corrosion products, as might be expected.

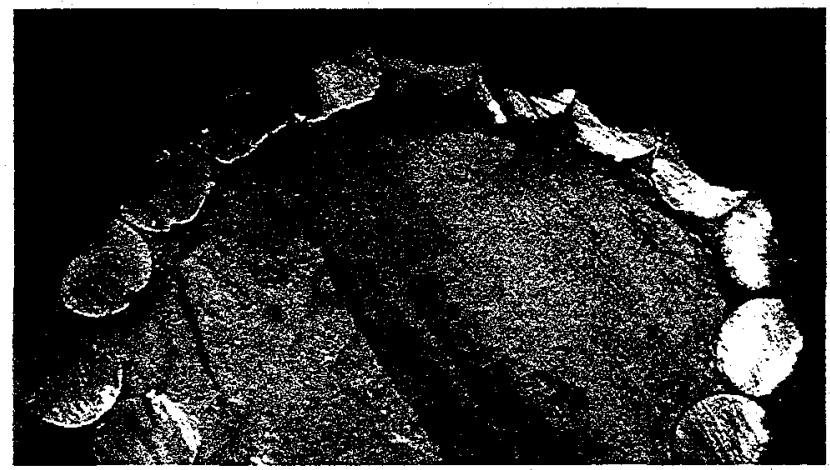

Figure 2. Upper part of steel tendon showing severe local corrosion.

\section{Review of literature}

Following these findings, an investigation was commenced to ascertain whether there were earlier reports, in the open literature, of cases of severe localized corrosion loss of reinforcement. The literature review took a considerable amount of time and involved many searches in old publications (Melchers and Li 2009a) but no further cases of excessive reinforcement corrosion without exterior evidence were uncovered. However, subsequent to the publication of Melchers et al. 2009), the authors were contacted by a number of individuals, from various parts of the world, who noted that in detailed inspection of older concrete structures they, too, had observed black rusts, sometimes soft in texture and the apparent complete loss of the original reinforcement, without obvious evidence of reinforcement corrosion on the external concrete surface. Surprisingly, this appears to have had no significant discussion in the literature, despite its obvious implications for safety assessments. It obviously is a matter for research attention.

The literature review also considered whether favourable long-term durability of reinforced concrete structures could be correlated with the presence of aggregates (fine or coarse) with elevated levels of alkalis such as calcium carbonate (for example as in seashells). Here the results were much more positive. Three categories were identified - (i) 
concretes with igneous or similar aggregates, (ii) concretes with limestone, dolomite or blast furnace slag aggregates and (iii) concretes made with blast furnace slag. Taking the last two together, the data are summarized on Normal distribution plots in Figure 3. These are based on 54 groups of data, some consisting of just one observation and others of up to 1000 elements. In all cases the influence of concrete mix and concrete cover, of average or range in temperature and local weather conditions was ignored and simply considered as part of the variability in the data. The severity of exposure to chlorides was considered but was only of secondary importance particularly for the time to active corrosion (Melchers and Li 2009a).

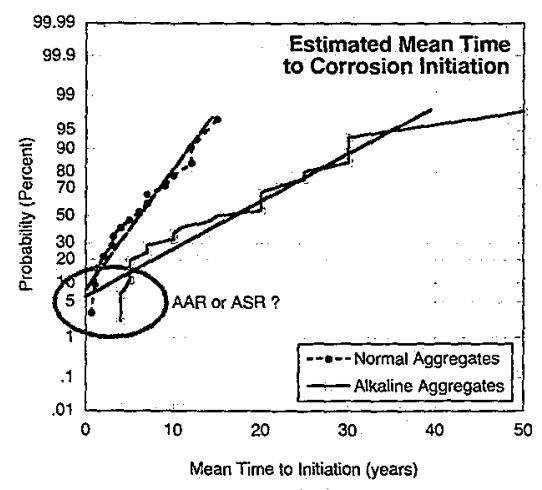

(a)

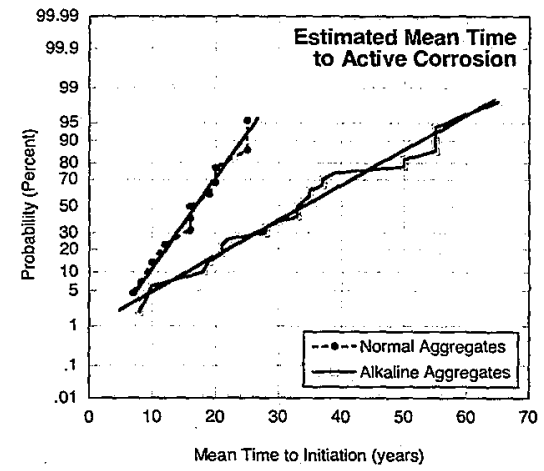

(b)

Figure 3. Normal cumulative probability plots for (a) time to initiation and (b) time to active corrosion showing normal aggregates and 'alkaline' aggregates.

The data trends in Figure 3 are in each case close to a Normal distribution. The slope of the trend line is proportional to the scatter in the data. In each case this is high, presumably because the influences of various potential factors was ignored (see above). Despite the scatter, there is a clear difference in the time to corrosion initiation for concretes made with igneous or similar non-high-alkaline aggregates and those with high levels of inherent alkalis. A large difference is seen also for the time to active corrosion. Both plots indicate that alkaline aggregates such as limestone, non-reactive dolomites, blast furnace slag and with blast furnace slag cements have a positive effect on delaying reinforcement corrosion, both its initiation and the onset of serious corrosion progression. Figure 3(a) shows also that some data may have been influenced a alkali-aggregate or alkali-silicate reactivity of the aggregate since these reactions cause early failure of the concrete and thus fail to provide sufficient protection. Failures of these types should not be considered as belonging to the same cohort of failures as those resulting primarily from reinforcement corrosion. More details are available (Melchers and Li 2010). 
Subsequently, it became apparent that there were a number of other cases for which the time to serious reinforcement corrosion was much longer than expected (Pape and Melchers 2008, Melchers 2010a, b, Melchers and Li 2010). The next section gives a recent example.

\section{An example - Concrete lighters, Sydney Harbour}

For reasons of safety reinforced concrete ammunition lighters (CALs) rather than more conventional vessels are the preferred mode of transportation for explosives and ammunition to front-line naval vessels during provisioning in port. The Australian Navy has retired a number of CALs from service and sold them on the open market. Many are still in very good condition. Many have found further use as tanks for fish-breeding and fish-farming. Six, dating from around 1970, became available for inspection during April 2009. These were 100 tonne and 200 tonne capacity and 27.7 and $32.6 \mathrm{~m}$ long, respectively and of cast construction (Figure 4). They had operated in Sydney Harbour in waters closely similar to coastal seawater.

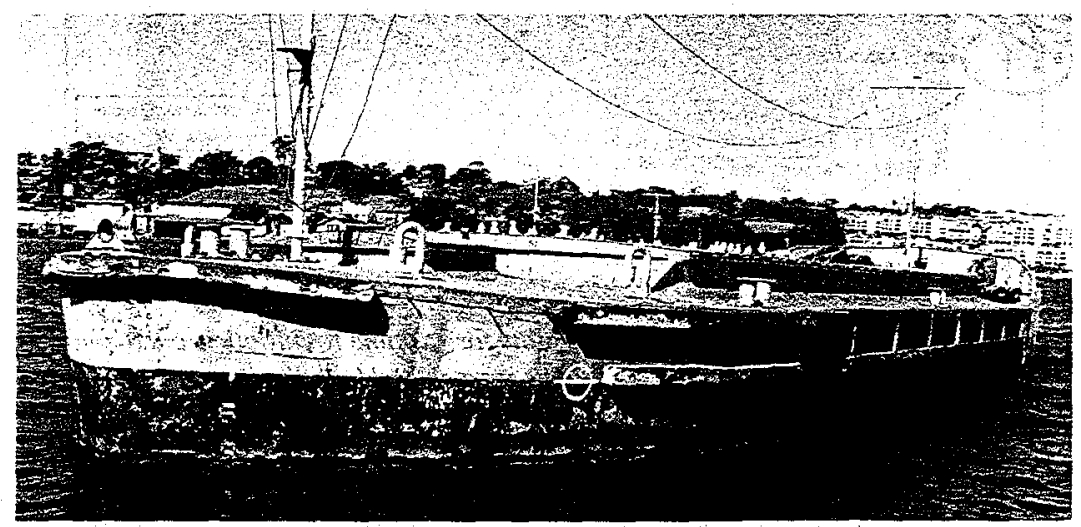

Figure 4. A 100 tonne concrete ammunition lighter (CAL) in Sydney Harbour.

Despite having been in service for some 40 years the CALs showed almost no reinforcement corrosion externally or internally. There were one or two very small areas where the reinforcement had been exposed (Figure 5). These showed local reinforcement corrosion but negligible rust staining or corrosion-induced cracking. The internal concrete surfaces were in excellent condition and free from evidence of reinforcement corrosion, with one notable exception (Figure 6). On one of the internal surfaces, there is brown rust and rust weeping and staining. XRD (X-ray diffraction analysis) showed these to be predominantly conventional rust oxides. There is no evidence of reinforcement corrosion on the corresponding exterior hull surface, only longitudinal cracking (Figure 7). 


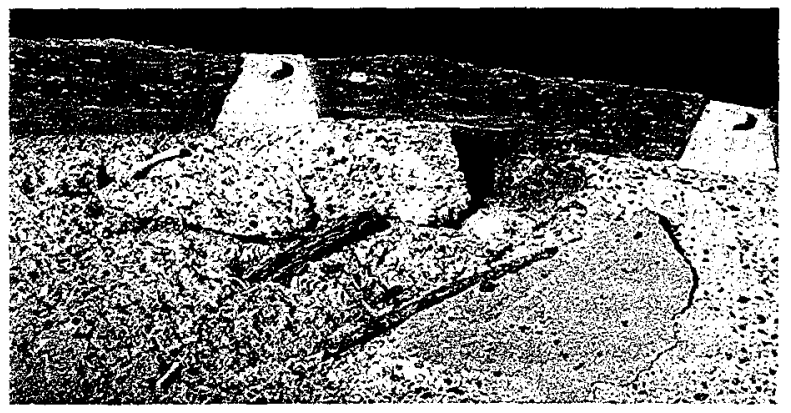

Figure 5. Exposed corroded reinforcement on deck showing no rust staining and carbonation of concrete.

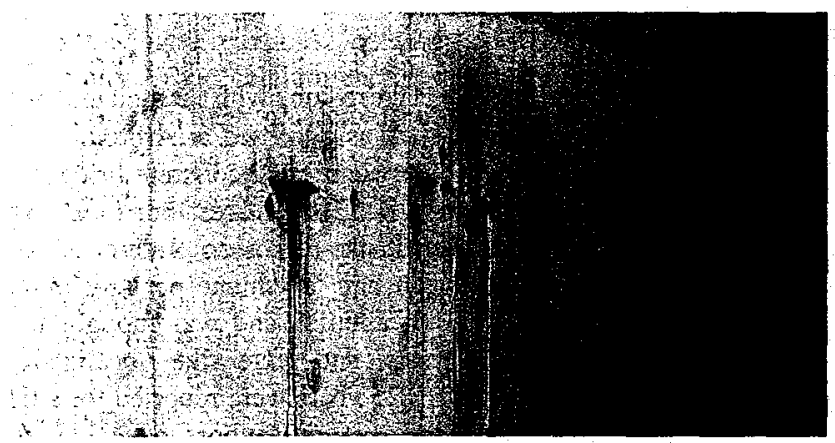

Figure 6. Interior of the only one of the six CALs showing internal rust staining.

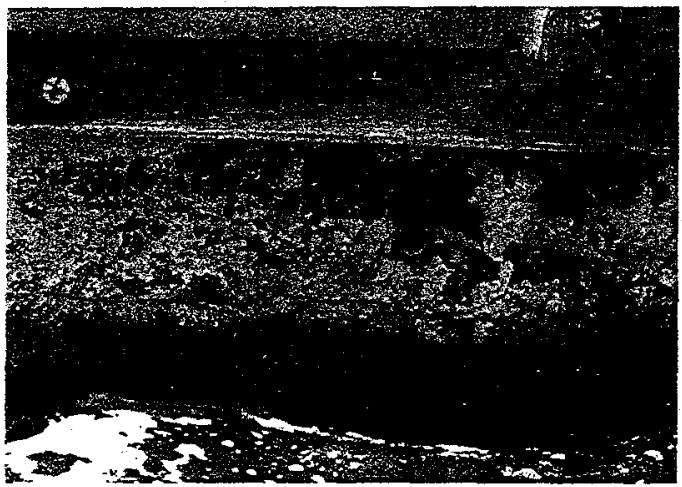

Figure 7. Exterior of CAL corresponding to rust stained region in Figure 6. Note horizontal crack above the water line level for unloaded vessel. 
These observations, apparently, are not atypical and had been found also for other CALs (Gary Webb, private communication 2009). When repairs were made for some of these by removal of local concrete cover, in some cases the original reinforcing bar(s) in the area were found to have been severely corroded, leaving only a trace of black corrosion product in the space(s) where the reinforcing bars had been. This is similar to what was found at Arbroath (Figure 1) and at Sorell.

The CALs had been built in Sydney and thus presumably local materials had been used. The coarse aggregates are very hard and most likely are basalt or related igneous rock, the predominant traditional coarse aggregates used in the Sydney region. The fine aggregate undoubtedly is Kurnell dune sand. This was by far the predominant source of sand for the construction industry in Sydney during 1930-1990s. It was easily obtained, of low cost and valued for its high crushed shell content and lack of organic matter (Wikipedia 2010).

\section{Discussion}

Isolated references to severe localized corrosion with associated black corrosion products but with little external evidence, such as observed at Arbroath and Sorell, were also found in the literature, including for older reinforced concrete bridges in the US and for reinforced concrete bridge decks in the UK. The clearest but brief exposition is by Cavalier and Vassie (1981) who noted 'the (black) corrosion product is not the common rust produced in general corrosion' and that it had 'a volume per unit mass substantially lower' than typical for rusts. It had a pH of about 5 and was thought to be similar to magnetite. Similar, unidentified black rusts and extensive localized corrosion of reinforcement concrete specimens exposed for 25 years were reported for a tidal pool in the UK. In investigations so far unreported, the present Authors have identified the black material as being $\mathrm{Fe}_{3} \mathrm{O}_{4}$ (magnetite) a hard black oxidation product, but they also have found evidence of $\mathrm{FeS}$, a soft black corrosion product usually associated with the presence of sulfate-reducing bacteria.

It should be clear that to elucidate what actually happens in practice field studies and field data are essential. Long-term behaviour cannot be replicated in short-term laboratory tests. Accelerated testing, such as using anodic polarization by electrochemical means, tends to change the electrochemistry involved. It also cannot be used when bacteria are considered to influence the corrosion process (Cord-Ruwisch 2000). This limits research to the few older structures available to researchers. Challenging also is the problem that breaking-up older concretes inevitably oxidizes corrosion products such as $\mathrm{FeS}$ and thus speed and ready availability of analysis equipment is essential. Breaking-up concrete specimens in an anoxic, sterile chamber might be the most desirable experimental approach, it also presents considerable challenges. Research in this area is on-going.

The field evidence of the apparent influence of aggregates such as sands with shell fragments, calcium carbonate or non-reactive dolomite coarse aggregates, or blast furnace slag aggregates, or the use of blast furnace slag cements, has support in controlled corrosion science experiments (Glass and Buenfeld 1997, Moreno et al. 2004, Huet et al. 2005) and in 
fundamental chemical thermodynamic considerations (Garrels and Christ 1965, Matthiesen et al. 2003). These support the notion that increasing the alkali content delays corrosion initiation, and reduces the rate of reinforcement corrosion. The details, accessible to engineers, are available (Melchers 2010b) and may be summarised as follows. It is important to remember in this that $\mathrm{pH}$ does not measure 'alkalinity', i.e. the buffering capacity of alkalis.

1. The alkalinity of the porewaters, that is, the buffering capacity of alkalis, determines when corrosion initiation will occur. Conventionally this has been associated only with the alkalinity derived from the reaction of the setting cement.

2. Laboratory studies show that calcium carbonate has a buffering effect and that higher concentrations of calcium carbonate inhibits the initiation of corrosion.

3. Under higher concentrations of calcium carbonate the presence of chloride ions does not have a strong influence on the initiation of corrosion.

4. Initiation of chemical reactions, including corrosion initiation, is determined by free energy considerations. When calcium carbonate can be involved in the chemical reaction there is the possibility to form protective $\mathrm{FeCO}_{3}$ (siderite). It will retain concrete $\mathrm{pH}$ at around 10 .

5. Fundamental corrosion science, thermodynamics and field observations show that corrosion initiation cannot commence until the local $\mathrm{pH}$ has dropped to about 9.

6. To lower the solution $\mathrm{pH}$, the most likely mechanism is leaching of the alkalis, noting that $\mathrm{KOH}$ and $\mathrm{NaOH}$ are highly soluble and that $\mathrm{Ca}(\mathrm{OH})_{2}$, normally of low solubility, has greater solubility in saline conditions. Other mechanisms, such as absorption by silica gels formed during carbonation, also may be involved.

7. The rate of alkali leaching is governed by concrete permeability and will be greater for washing of external concrete surfaces by rainfall or water currents.

Taken together, these points go a long way to explaining observations for long-term exposures of reinforced concrete structures in realistic environments, as distinct from shortterm laboratory observations.

A further matter of interest is the influence of seawater as mixing water. Obviously, salt is hygroscopic and this may increase the 'time of wetness' for situations where the concrete cover is no longer effective. But it is easily demonstrated that for the conventional oxidation reaction of iron $(\mathrm{Fe})$ with water $\left(\mathrm{H}_{2} \mathrm{O}\right)$ and oxygen $\left(\mathrm{O}_{2}\right), \mathrm{NaCl}$ is not directly involved - the chloride ions are 'spectators' in the corrosion rate process. This raises the question about the importance of seawater as mixing water.

The work, for example of Shalom and Raphael (1959) showed seawater to be deleterious as mixing water, and is referred to repeatedly in the reinforced concrete corrosion literature. However, their findings were based in short term exposures of samples in the laboratory. Subsequent contrary findings, in real marine exposure conditions, appear to have been ignored. For example, in a little-known paper, Boqi et al. (1983) reported that 
concrete samples made to realistic specifications but with seawater both as mixing water and for curing initially showed greater corrosion (after 3 years exposure) but that this was not the case after 5 years exposure. After 10 years exposure the reinforcement corrosion area and the average corrosion rates were about one third of those for concretes with fresh water mixing waters. The observations at Arbroath are consistent with these. Interestingly, the concretes used by Shalom and Raphael (1959) and by Boqi et al. (1983) had limestone aggregates and the 1943 Arbroath concrete included seashells.

Finally, it should be clear that the presence of calcium carbonate in concretes in marine environments, sometimes thought to be a result of 'carbonation', are much more likely to be the direct result of deposition. This occurs on concrete surfaces and within porous concretes of high $\mathrm{pH}$, since seawater is well-known to be (super-) saturated with carbonates $\left(\mathrm{CaCO}_{3}\right.$ and $\mathrm{MgCO}_{3}$ ) (Melchers 2010a). It follows that 'carbonation' by itself does not lower the concrete $\mathrm{pH}$ sufficiently adjacent to the reinforcement to permit corrosion initiation. Leaching of alkalies is required to occur before corrosion can initiate.

\section{Conclusion}

The available evidence suggests that one of the components of concrete - the aggregate has been forgotten in attempts to explain the long-term corrosion resistance of reinforcing bars in concretes exposed to marine conditions. The accumulated data, despite its variability, shows that the presence of alkali aggregates such calcium carbonate, nonreactive dolomite, or sands containing seashell fragments can boost the alkali reserves of the concrete and thus delay the initiation and the rate of reinforcement corrosion. This is provided other deterioration mechanisms such as alkali-aggregate reactivity do not interfere. Also, basic chemistry considerations show that the effect of chlorides on reinforcement corrosion initiation is likely to be much less in real seawaters because of their usually supersaturated levels of carbonates. Finally, there is now convincing evidence that severe reinforcement corrosion can occur without external evidence such as cracking, spalling and concrete delamination. Taken together, these various observations have important practical implications for the prediction of the life of reinforced concrete structures.

\section{Acknowledgements}

The authors acknowledge the financial support provided by a Discovery Grant from the Australian Research Council. They are indebted also to Gary Webb, Marine Surveyor, the Australian Navy and Defence Maritime Services for facilitating access to the CALs in Sydney Harbour, the Department of Infrastructure, Energy and Resources, Tasmania and Mark Davidson, Tayside Regional Council, Scotland. 


\section{References}

Cavalier, P.G. and Vassie, P.R. (1981) Investigation and repair of reinforcement corrosion in a bridge deck, Proc Instn Civ Engrs, Part 1, 70: 461-480.

Cord-Ruwisch, R. (2000) Microbiologically Influenced Corrosion, (In) Environmental Microbe-Metal Interactions (Ed.) D.R. Lovely, Washington: ASM Press, 159-173.

Garrels, R.M. and Christ, C.L. (1965) Solutions, minerals, and equilibria, New York: Harper \& Row.

Gjorv, O.E. (2009) Durability design of concrete structures in severe environments, London: Taylor \& Francis.

Glass, G.K. and Buenfeld, N.R. (1997) The presentation of the chloride threshold level for corrosion of steel in concrete, Corrosion Science 39(5) 1001-1013.

Huet, B., L'Hostis, V., Miserique, F. and Idrissi, H. (2005) Electrochemical behavior of mild steel in concrete: influence of $\mathrm{pH}$ and the carbonate content of the pore solution, Electrochimica Acta, 51(1) $172-180$.

Hunkeler, F. (2005) Corrosion in reinforced concrete: processes and mechanisms, (In) Corrosion in reinforced concrete structures, (Ed) H. Bohni, Cambridge: Woodhead, 1-45.

Matthiesen, H., Hilbert, L.R and Gregory, D.J. (2003) Siderite as a corrosion product on archaeological iron from waterlogged environment, Studies in Conservation 48: 183-194.

Melchers, R.E. (2010a) Observations about the time to commencement of reinforcement corrosion for concrete structures in marine environments, CONSEC2010, Mexico.

Melchers, R.E. (2010b) Carbonates, carbonation and the durability of reinforced concrete marine structures, Australian Journal of Structural Engineering, (to appear).

Melchers, R.E. \& Li, C.Q. (2009a) Reinforcement corrosion initiation and activation times in concrete structures exposed to severe marine environments, Cement and Concrete Research, 39: 1068-1076.

Melchers, R.E. and Li, C.Q. (2009b) Reinforcement corrosion in concrete exposed to the North Sea for over 60 years, Corrosion, $65(8)$ 554-566.

Melchers, R.E. and Li, C.Q. (2010) Predicting the life o reinforced concrete structures in severe marine environments, $L A B M A S$ conference, USA.

Melchers, R.E., Li, C.Q. and Davison, M.A. (2009) Observations and analysis of a 63-year old reinforced concrete promenade railing exposed to the North Sea, Magazine of Concrete Research, 61(4) 233-243.

Moreno, M., Morris, W., Alvarez, M. G. and Duffó, G. S. (2004) Corrosion of reinforcing steel in simulated concrete pore solutions: Effect of carbonation and chloride content. Corrosion Science 46 (11) $2681-2699$.

Pape, T. and Melchers, R.E. (2008) Investigating the effects of corrosion on 45-year-old prestressed concrete bridge beams. IALCCE'08: First International Symposium on Life-Cycle Civil Engineering, London, Taylor \& Francis, CDROM.

Richardson, M.G. (2002) Fundamentals of durable reinforced concrete, London: Spon. 
Shalom, R. and Raphael, M. (1959) Influence of sea water on corrosion of reinforcement, Journal of the American Concrete Institute, 30(12) 1251-1268.

Wikipedia (2010) http://en.wikipedia.org/wiki/Cronulla_sand_dunes,_Kurnell_Peninsula - last accessed 18 Feb 2010. 